

\title{
Homogeneous electrochemical monitoring of exonuclease III activity and its application to nucleic acid testing by target recycling
}

Rebeca Miranda-Castro, Damien Marchal, Benoît Limoges, François Mavré

\section{- To cite this version:}

Rebeca Miranda-Castro, Damien Marchal, Benoît Limoges, François Mavré. Homogeneous electrochemical monitoring of exonuclease III activity and its application to nucleic acid testing by target recycling. Chemical Communications, 2012, 48 (70), pp.8772-8774. 10.1039/c2cc34511k . hal-01297708

\section{HAL Id: hal-01297708 \\ https://hal.science/hal-01297708}

Submitted on 6 Apr 2016

HAL is a multi-disciplinary open access archive for the deposit and dissemination of scientific research documents, whether they are published or not. The documents may come from teaching and research institutions in France or abroad, or from public or private research centers.
L'archive ouverte pluridisciplinaire HAL, est destinée au dépôt et à la diffusion de documents scientifiques de niveau recherche, publiés ou non, émanant des établissements d'enseignement et de recherche français ou étrangers, des laboratoires publics ou privés. 


\section{Homogeneous electrochemical monitoring of exonuclease III activity and its application to nucleic acid testing by target recycling $\dagger$}

\author{
Rebeca Miranda-Castro, Damien Marchal, Benoît Limoges* and François Mavré* \\ Received 23rd June 2012, Accepted 4th July 2012 \\ DOI: $10.1039 / \mathrm{c} 2 \mathrm{cc} 34511 \mathrm{k}$
}

A simple and fast electrochemical nucleic acid assay based on a target recycling strategy and the release of a double-stranded DNA intercalating redox probe upon digestion of a specific duplex by exonuclease III is demonstrated.

The development of portable, easy-to-use, fast, and inexpensive sensitive nucleic acid assays for point-of-care analysis of pathogenic agents is an important step forward in public health, forensic analysis, food industry or environmental monitoring. ${ }^{1}$ Among the different strategies proposed for the development of such nucleic acid assays, isothermal nucleic acid amplification-based technologies, including LAMP, EXPAR, RPA, HDA, and MDA, were the most widely considered for the reason that they are very sensitive and specific. ${ }^{2}$ They however require precise temperature control as well as complex sets of primers, enzymes and handling procedures which restrict their scope of applications. Methods based on signal amplification instead of target amplification are an attractive and much simpler alternative, in particular those based on DNA target recycling wherein a nucleic acid sequence takes part in multiple hybridization events to achieve a greatly enhanced sensitivity. The target recycling reaction can be achieved both with nicking endonucleases ${ }^{3}$ or exonucleases. ${ }^{4}$ These enzymes allow selective hydrolysis of an oligonucleotide probe hybrized to the target nucleic acid sequence, which in turn releases the intact target template for further rounds. In the case of nicking endonucleases, the oligonucleotide probe is cleaved at a specific nucleotide position, restricting thus possibilities in terms of probe design and choice of DNA target. In an attempt to overcome this limitation, new restriction endonucleases have been proposed ${ }^{5}$ as well as clever probe designs. ${ }^{6}$ However, a relatively high level of temperature control is still required for the selective melt of cleaved probes. The use of an exonuclease III (Exo III) for DNA target recycling appears to be a more versatile approach. ${ }^{7}$ This enzyme has the particularity to specifically catalyse the stepwise removal of

Laboratoire d'Electrochimie Moléculaire, UMR 7591 CNRS,

Université Paris Diderot, Sorbonne Paris Cité,

15 rue Jean-Antoine de Baif, F-75205 Paris Cedex 13, France.

E-mail: francois.mavre@univ-paris-diderot.fr; Fax: + 33 157278788;

Tel: +33157278789

$\dagger$ Electronic supplementary information (ESI) available: Experimental details as well as results for probe optimizations and selectivity experiments. See DOI: $10.1039 / \mathrm{c} 2 \mathrm{cc} 34511 \mathrm{k}$ mononucleotides from blunt or recessed 3'-hydroxyl termini of double-stranded DNA (dsDNA), irrespective of the sequence present at the $3^{\prime}$ end. Since Exo III works efficiently at low temperature, target recycling can be simply done at room temperature.

Okano and Kambara were the first to demonstrate the principle of DNA target recycling by Exo III in combination with a fluorescence detection method. ${ }^{4 a}$ Since then, the Exo III-aided target recycling strategy has been adapted to diverse optical assay formats (homogeneous ${ }^{8}$ and heterogeneous ${ }^{4 b}$ ) as well as different types of labeled oligonucleotide probes (stem-loop ${ }^{4 c}$ or linear ${ }^{9}$ molecular beacons, displacing probes ${ }^{10}$ ) or reporter nanomaterials. ${ }^{11}$ Although fluorescent-based optical detection methods were the most widely used, they are not so easily amenable to the development of cost-effective and low-power handheld readout devices. By comparision, electrochemical detection methods can overcome these limitations since they are inherently more robust, simpler, less expensive and easier to miniaturize than optical ones, with the further advantages of being able to work with cloudy and/or colored samples. Until now, very few efforts have been made to combine the advantages of an electrochemical readout with a DNA target recycling amplification, and most of them were based on a heterogeneous assay wherein the target recycling process occurs directly on the electrode surface. ${ }^{12}$ The problem with heterogeneous formats is their higher complexity and demand in terms of electrode preparation, as well as their slower DNA hybridization and enzyme kinetics compared with homogeneous assays. The development of faster and easier-to-use electrochemical detection strategies such as those taking advantage of homogeneous DNA hybridization remains thus highly desirable. Very recently, a homogenous electrochemical assay based on an Exo III-aided target recycling strategy has been developed by Hsing and colleagues. ${ }^{13}$ Their approach is based on the detection of a redox label that is released by Exo III upon hydrolysis of a redox-labeled oligonucleotide probe. Although interesting, the method needs the chemical coupling of a redox label to an oligonucleotide probe.

In the present work, we propose a homogeneous label-free electrochemical detection strategy which relies on a DNA target recycling amplification through the specific Exo III-digestion of a non-labeled oligonucleotide probe and an electrochemical readout which takes advantage of the difference in diffusion rates between a free and a bound dsDNA-intercalating 


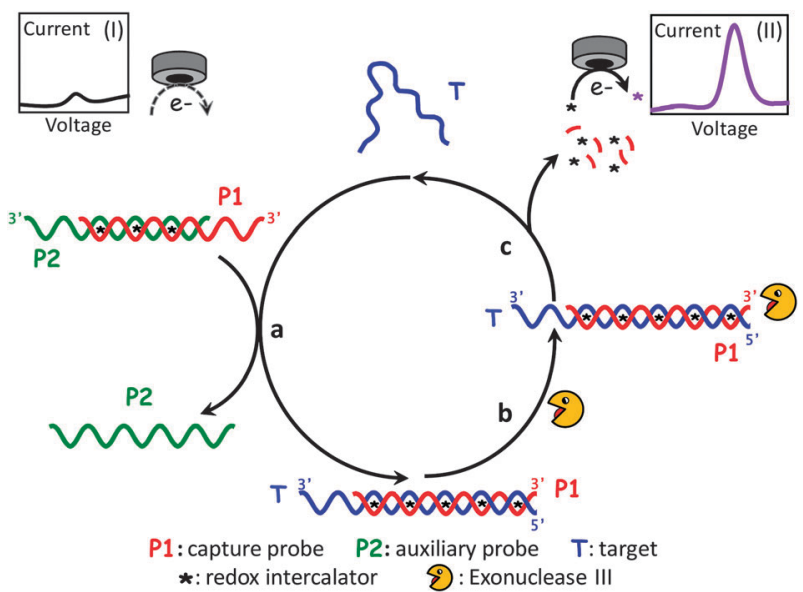

Scheme 1 Principle of the Exo III-aided target recycling strategy and its associated homogeneous electrochemical detection.

redox probe. The method is exemplified for the detection of a DNA sequence specific to the Salmonella typhimurium bacterium, one of the main organisms causing the outbreaks of foodborne illnesses.

The principle of the method is depicted in Scheme 1. It consists in starting from a short dsDNA reservoir (P1-P2) in which an intercalating redox probe is bound. After adding (a) the target sequence $\mathbf{T}$ and forming a thermodynamically more stable P1-T duplex (having a $3^{\prime}$-blunt end at P1 and a protective $3^{\prime}$-protruding end at $\mathbf{T}$ ), (b) the Exo III can selectively digest the $\mathbf{P 1}$ probe from the blunt $3^{\prime}$ end of the complementary P1-T duplex, thereby (c) releasing T for a new catalytic cycle. The catalytic reaction triggered by the addition of $\mathbf{T}$ thus leads to consumption of the P1-P2 reservoir which in turns allows continuous release of the intercalating redox probe into the bulk solution. Assuming that the free intercalating redox probe is more easily electrochemically detected than the intercalated one, the enzyme reaction should thus lead to a current response increase for an electrode immersed in the reaction mixture. As a P1-P2 duplex, a 15-bp dsDNA protected against Exo III activity by 3 '-protruding ends at both strands was selected and designed for selectively hybridizing to a 37-mer target sequence $\mathbf{T}$ specific to the $S$. typhimurium bacterium (DNA sequences are listed in Table $\mathrm{S} 1$ in ESI $\dagger$ ). As an intercalating redox probe, we have used the Os[(bpy $\left.)_{2}(\mathrm{dppz})\right]^{2+}$ complex (where bpy $=2,2^{\prime}$-bipyridine and dppz $=$ dipyrido$\left[3,2-a: 2^{\prime}, 3^{\prime}\right.$-c]phenazine), the latter being known to strongly intercalate in dsDNA and being sensitively detected by square wave voltametry (SWV) down to a few nanomolar. ${ }^{14}$

As shown in Fig. 1A, in the presence of $0.8 \mu \mathrm{M}$ P1-P2 duplex, the SWV response of $2 \mu \mathrm{M} \mathrm{Os}\left[(\mathrm{bpy})_{2}(\mathrm{dppz})\right]^{2+}$ (a, green curve) is drastically diminished (b, black curve) because of intercalation of the osmium complex into the dsDNA. The signal decrease reflects thus the lower accessibility of the dsDNA-bound redox probe as well as its lower rate of diffusion to the electrode. Addition of $2 \mathrm{U}^{-1}$ of Exo III to the mixture does not substantially change the SWV signal (c, red curve), indicating that the duplex reservoir protected at its $3^{\prime}$-end is not significantly hydrolyzed by Exo III. This is in contrast to the large SWV peak current increase obtained after the addition of $100 \mathrm{nM} \mathrm{T}$ (d, blue curve).
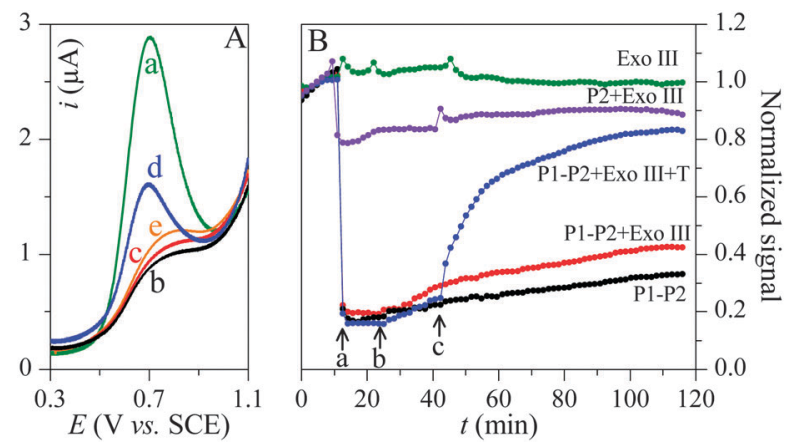

Fig. 1 (A) SWV curves recorded after successive additions of (a, green) $2 \mu \mathrm{M}\left[\mathrm{Os}(\mathrm{bpy})_{2}(\mathrm{dppz})\right]^{2+}$, (b, black) $0.8 \mu \mathrm{M}$ P1-P2, (c, red) $2 \mathrm{U} \mu \mathrm{L}^{-1}$ Exo III, and (d, blue and e, orange) $100 \mathrm{nM} \mathrm{T}$ or $\mathbf{R}$, respectively. (B) Real-time monitoring of the integrated SWV peak currents of $2 \mu \mathrm{M}\left[\mathrm{Os}(\mathrm{bpy})_{2}(\mathrm{dppz})\right]^{2+}$ as a function of time and successive additions of (blue curve) (a) P1-P2 duplex, (b) Exo III, and (c) T. The other plots are control experiments where some of the components were omitted (for details see Table S2 in ESI $\dagger$ ).

This increase indicates that the triggering of catalytic reaction through the specific displacement of $\mathbf{P 2}$ by $\mathbf{T}$ with concomitant formation of the 27-bp P1-T duplex leads to the release of intercalated redox probes by selective digestion of P1. Since several intercalating redox probes can be released per each duplex reservoir during a single hybridization-hydrolysis cycle, a more highly sensitive electrochemical detection can thus be expected compared with a strategy involving a singlelabeled oligonucleotide probe. Such a catalytic reaction finally leads to a first order rate amplification of the electrochemical response as a function of time as soon as the duplex reservoir is not too much depleted. The specificity of the reaction was confirmed by the absence of signal increase when the target is substituted by a random non-complementary DNA sequence $\mathbf{R}$ (e, orange curve). A further control experiment was done with the Exo III beforehand deactivated at $70{ }^{\circ} \mathrm{C}$ for $20 \mathrm{~min}$. In this case no signal change could be observed (data not shown).

To have a real-time analysis, the enzyme kinetic reaction was monitored in a custom designed electrochemical microtiter plate ${ }^{14 b}$ with 48 independent microwells (working volume of $50 \mu \mathrm{L}$ ), all being able to be adressed quasi-simultaneously by SWV. A series of kinetic plots showing the integrated SWV peak current as a function of time (recorded here every 94 seconds) is given in Fig. 1B. The blue curve shows the progression of a typical Exo III-aided target recycling amplification. Starting from $2 \mu \mathrm{M}$ osmium complex in the digestion buffer, successive

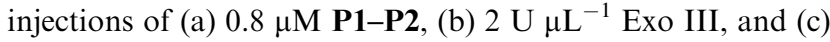
$100 \mathrm{nM}$ T were done. In parallel, different control experiments were conducted to determine the possible influence of each assay component on the electrochemical response. In the presence of $\mathbf{T}$, a concentration-dependent signal increase was systematically observed, with a tendency to asymptotically reach a value similar to the one obtained when only $\mathbf{P 2}$ is in solution (violet curve), a situation corresponding thus to the total digestion of P1. In that experiment, the signal value slightly decreased after the injection of P2, suggesting an interaction of the osmium complex with the ssDNA (probably by electrostatic binding). The remaining SWV response finally represents the maximal recoverable signal. Two different 

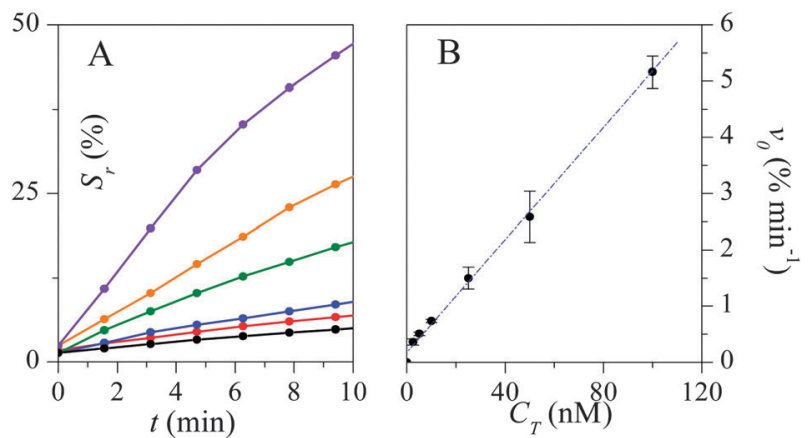

Fig. 2 (A) Time-dependent signal recovery $\left(S_{\mathrm{r}}\right)$ for different target concentrations (from bottom to top: $2.5,5,10,25,50$, and $100 \mathrm{nM} \mathrm{T}$ ). Experiments were performed in the presence of $1 \mathrm{U}^{-1} \mathrm{~L}^{-1}$ Exo III, $2 \mu \mathrm{M}\left[\mathrm{Os}(\mathrm{bpy})_{2}(\mathrm{dppz})\right]^{2+}$ and $0.8 \mu \mathrm{M}$ of P1-P2. (B) Plot of the signal recovery rate $\left(v_{0}\right)$ as a function of target concentrations.

kinetic phases were observed for the enzymatic reaction (blue curve in Fig. 1B), i.e. an initial burst of hydrolysis ( $50 \%$ of the signal is recovered in less than $10 \mathrm{~min}$ ) followed by a slower DNA digestion (an additional $1 \mathrm{~h}$ period is required to achieve the level-off). Assuming that the total recovery corresponds to the complete digestion of $0.8 \mu \mathrm{M} \mathrm{P1}$, the kinetics of nucleotide hydrolysis for the initial phase is around $50 \mathrm{pmol}$ nucleotide per minute, a value in line with former kinetic measurements. ${ }^{15}$

The kinetic plots were repeated for different target DNA concentrations ranging from $2.5 \mathrm{nM}$ to $100 \mathrm{nM}$, and the percentage of signal recovery $\left(S_{\mathrm{r}}\right)$ with time is reported in Fig. 2A. The initial recovery rates $\left(v_{0}\right)$ obtained from the slopes of the kinetic plots vary linearly with the target DNA concentration within the range $0-100 \mathrm{nM}\left[v_{0} / \% \mathrm{~min}^{-1}=\right.$ $\left.(5.0 \pm 0.1) \times 10^{-3} C_{\mathrm{T}} / \mathrm{nM}+(0.18 \pm 0.05) ; r=0.998 ; n=7\right]$ (Fig. 2B). The detection limit for the sensing system is $2.5 \mathrm{nM}$, and the assay reproducibility $15 \%$. A key factor affecting the detection limit is the possible slow nonspecific digestion of the P1-P2 duplex. Different Exo III-resistant $3^{\prime}$-protruding ends were thus designed and tested, considering not only the influence of the tail length but also its base sequence (Fig. S2, ESI $\dagger$ ). Some of the selected sequences were observed better for reducing the nonspecific hydrolysis. The assay selectivity was finally evaluated from comparative study between the perfectly matched $\mathbf{T}$ sequence and a double $\left(\mathbf{M}_{2}\right)$ or triple $\left(\mathbf{M}_{3}\right)$ mismatched sequence. Under the same experimental conditions, the signal recovery rate for $\mathbf{M}_{2}$ was found to be $40 \%$ lower than the one obtained for $\mathbf{T}$, meanwhile no signal recovery was observed for $\mathbf{M}_{3}$ (see Fig. S3, ESI $\dagger$ ).
In summary, we have demonstrated the feasibility of a homogeneous, label-free, single-step, electrochemical assay for the specific detection of a nucleic acid sequence at room temperature by target recycling amplification. This has been illustrated with the quantitative assay of a $S$. typhimurium specific DNA sequence down to nanomolar concentration (i.e., $\sim 0.1$ pmol in $50 \mu \mathrm{L}$ ) in less than $10 \mathrm{~min}$, which is competitive with optical DNA assays that use linear amplification by target recycling. On account of the sequenceindependent Exo III activity this methodology might be extended to the detection of a wide range of nucleic acid targets, as well as small molecules or proteins able to specifically interact with structured nucleic acids (e.g., aptamers).

R. Miranda-Castro thanks Fundación Ramón Areces for a post-doctoral grant.

\section{Notes and references}

1 A. Niemz, T. M. Ferguson and D. S. Boyle, Trends Biotechnol., 2011, 29, 240.

2 P. Craw and W. Balachandran, Lab Chip, 2012, 12, 2469.

3 (a) J. W. J. Li, Y. Z. Chu, B. Y. H. Lee and X. L. S. Xie, Nucleic Acids Res., 2008, 36, e36; (b) W. Xu, X. Xue, T. Li, H. Zeng and X. Liu, Angew. Chem., Int. Ed., 2009, 48, 6849.

4 (a) K. Okano and H. Kambara, Anal. Biochem., 1995, 228, 101; (b) H. J. Lee, Y. Li, A. W. Wark and R. M. Corn, Anal. Chem., 2005, 77, 5096; (c) X. L. Zuo, F. Xia, Y. Xiao and K. W. Plaxco, J. Am. Chem. Soc., 2010, 132, 1816.

5 (a) B.-C. Yin, Y.-Q. Liu and B.-C. Ye, J. Am. Chem. Soc., 2012, 134, 5064; (b) X. Xiao, C. Song, C. Zhang, X. Su and M. Zhao, Chem. Commun., 2012, 48, 1964.

6 (a) S. Nakayama, L. Yan and H. O. Sintim, J. Am. Chem. Soc., 2008, 130, 12560; (b) Q. Wang, L. Yang, X. Yang, K. Wang, L. He, J. Zhu and T. Su, Chem. Commun., 2012, 48, 2982; (c) Y. V. Gerasimova, S. Peck and D. M. Kolpashchikov, Chem. Commun., 2010, 46, 8761 .

7 (a) C. C. Richardson, I. R. Lehman and A. Kornberg, J. Biol. Chem., 1964, 239, 251; (b) A. Kornberg, DNA Replication, (2nd edn), paperback edition, ch. 13, 2005.

8 (a) M. Zhang, Y. Guan and B.-C. Ye, Chem. Commun., 2011, 47, 3478; (b) C. Zhao, L. Wu, J. Ren and X. Qu, Chem. Commun., 2011, 47, 5461.

9 C. Yang, L. Cui, J. Huang, L. Yan, X. Lin, C. Wang, W. Zhang and H. Kang, Biosens. Bioelectron., 2011, 29, 119.

10 L. Cui, G. Ke, C. Wang and C. J. Yang, Analyst, 2010, 135, 2069.

11 (a) R. Freeman, X. Liu and I. Willner, Nano Lett., 2011, 11, 4456; (b) H. Chen, J. Wang, G. Liang, P. Zhang and J. Kong, Chem. Commun., 2012, 48, 269; (c) L. Zhang, S. Guo, S. Dong and E. Wang, Anal. Chem., 2012, 84, 3568.

12 (a) D. Wu, B.-C. Yin and B.-C. Ye, Biosens. Bioelectron., 2011, 28, 232; (b) Y. Chen, B. Jiang, Y. Xiang, Y. Chai and R. Yuan, Chem. Commun., 2011, 47, 12798.

13 F. Xuan, X. Luo and I.-M. Hsing, Anal. Chem., 2012, 83, 1815.

14 (a) T. Deféver, M. Druet, D. Evrard, B. Limoges and D. Marchal, Anal. Chem., 2011, 83, 1815; (b) F. Kivlehan, F. Mavré, L. Talini, B. Limoges and D. Marchal, Analyst, 2011, 136, 3635.

15 J. D. Hoheisel, Anal. Biochem., 1993, 209, 238. 